Cómo citar este artículo en MLA: Cuéllar Aragón, Danny. "Lenguaje y representación en la predictadura uruguaya: una lectura de Indicios pánicos, de Cristina Peri Rossi”. Escritos 28. 60 (2020): 48-61. doi: http://dx.doi.org/10.18566/escr.v28n60.a04

Fecha de recepción: 23.02 .2020

Fecha de aceptación: 15.05 .2020

\title{
Lenguaje y representación en la predictadura uruguaya: una lectura de Indicios pánicos, de Cristina Peri Rossi
}

\author{
Language and Representation during Uruguayan Pre-dictatorship: \\ A Reading of Cristina Peri Rossi's Panic Signs
}

\author{
Danny Cuéllar Aragón ${ }^{1}$ (두
}

\begin{abstract}
RESUMEN
El siguiente artículo parte de la indagación sobre el papel del lenguaje en la obra Indicios pánicos, de Cristina Peri Rossi. La hipótesis que se plantea para escribir el trabajo de investigación señala que el lenguaje, en tanto dispositivo mimético de representación y creación, constituye una forma de actualizar las relaciones de poder en la predictadura uruguaya. Para desplegar tal hipótesis se siguió una ruta metodológica cualitativa con enfoque hermenéutico y se plantearon algunos objetivos: i) reconstruir los antecedentes de la dictadura encabezada por Juan María Bodaberry, ii) inscribir la obra dentro de la tradición literaria de la narrativa del dictador con el enfoque sociocrítico de George Lukács y la teoría del campo de Pierre Bourdieu, iii) explicar, a partir de algunos autores, el funcionamiento del lenguaje como mecanismo de representación y poder, iv) analizar la obra de la escritora uruguaya a la luz del marco conceptual arriba enunciado. Se concluye en primer lugar que la obra, en efecto, responde a un lenguaje mimético de representación que implica una toma de posición a la que subyacen las nociones de hegemonía y contrahegemonía. Finalmente, se concluye que ante una crítica escasa por las situaciones coyunturales a las que se vio abocada la obra, el presente artículo constituye un valioso aporte al campo de la crítica literaria.
\end{abstract}

Palabras clave: Lenguaje; Predictadura uruguaya; Representación; Mímesis; Creación; Indicios; Peri Rossi; Bodaberry.

1 Magíster en Literatura, Universidad de los Andes, Colombia. Profesor del Departamento de Humanidades y Formación Integral de la Universidad Santo Tomás, sede Bogotá. Integrante del grupo de investigación Ieshfaz. El texto es resultado del seminario de formación docente "Narrativas del conflicto y del dictador" auspiciado por la Universidad Santo Tomás. Correo electrónico: dannycuellar@usantotomas.edu.co / d.cuellar138@uniandes.edu.co. 


\begin{abstract}
The article inquires about the role of language in Cristina Peri Rossi's Panic Signs [Indicios pánicos]. The hypothesis of the work is that language, as a mimetic instrument of representation and creation, established itself as a way to upgrade the relations of power during the Uruguayan pre-dictatorship. Being a qualitative research based on a hermeneutical approach, the article has the following aims: i) reconstruct the background to the dictatorship leaded by Juan Maria Bordaberry, ii) frame the work within the tradition of dictator novel following Lukács' socio-critical approach and Pierre Bourdieu's field theory, iii) explain how language works as an instrument of representation and power, iv) analyze Peri Rossi's work in the light of the aforementioned framework. It concludes, first, that the work responds to a mimetic language of representation, which involves taking a stance that is based on the notions of hegemony or counter-hegemony; and, second, that provided the scarce studies concerning the circumstantial situations of the work, the article might be regarded as a significant contribution to literary criticism.
\end{abstract}

Keywords: Language; Uruguayan Pre-dictatorship; Representation; Mimesis; Creation; Signs; Cristina Peri Rossi; Juan María Bordaberry.

\title{
Introducción
}

$\mathrm{P}$ or lo general, cuando se describen las lógicas dictatoriales se piensa en formas evidentes de dominar y, en ciertos casos, de eliminar al otro: el miedo, la violencia física y la restricción a los derechos humanos son el común denominador en este tipo de regímenes. Sin embargo, no resulta tan común analizar el rol que cumple uno de los mecanismos más 'sutiles' en las dinámicas de resistencia-dominación subyacentes al funcionamiento del poder dictatorial: el papel ambivalente que juega el lenguaje. El propósito del siguiente artículo consiste en demostrar que el lenguaje, entendido desde la representación y la creación, constituye en Indicios pánicos, obra escrita por la uruguaya Cristina Peri Rossi y publicada por primera vez en 1970, una modalidad de, en términos de Bourdieu, actualizar las relaciones de poder en el contexto de la predictadura uruguaya. Para argumentar esta hipótesis de trabajo se abordarán apartes históricos del país latinoamericano, se explorará la idea de lenguaje como representación y se analizarán algunos relatos de la obra a la luz de ciertos postulados teóricos que contribuirán al desarrollo temático.

\section{Contexto histórico literario}

La dictadura uruguaya recibe el mote de cívico-militar porque se origina en medio de un escenario legal en el que confluyen la elección democrática de Juan María Bordaberry, en 1971, como presidente, las medidas constitucionales de excepción, la intromisión paulatina de las Fuerzas Armadas en la vida de los civiles y, en general, un marco jurídico que permite concentrar el poder en el Ejecutivo. De acuerdo con Álvaro Rico la declaración de la "guerra interna" es un acontecimiento que ilustra "la coincidencia de la lógica política y la lógica militar, a los efectos de legalizar ese estatus bélico, así como la mayor injerencia de la Justicia militar y el papel de las Fuerzas Armadas como fuerza beligerante en todo el territorio nacional" (48). Precisamente, el 27 de junio de 1973 en compañía de algunos ministros, y amparado por la figura de Estado de emergencia, Bordaberry, mediante decreto 464/973, disuelve las Cámaras electas de Representantes y Senadores, y en su reemplazo crea un Consejo de Estado, conformado por 25 integrantes elegidos por el presidente (Comisión Interamericana de Derechos Humanos, 1978). El artículo 
3 del mismo decreto señala como prohibida la divulgación, por medio de prensa escrita o televisada, de "todo tipo de información, comentario o grabación que, directa o indirectamente, mencione o se refiera a lo dispuesto por el presente decreto atribuyendo propósitos dictatoriales al Poder Ejecutivo, o pueda perturbar la tranquilidad y el orden público" (ctd. en Blengio 136). El nuevo presidente, consciente del poder del lenguaje, pretendía negar lo evidente: la imposición de una dictadura, que, a diferencia de otros casos latinoamericanos, no fue asumida por la "Junta de Comandantes de las Fuerzas Armadas, ni por una figura militar, sino que se mantuvo al civil que en las elecciones de 1971 había sido electo Presidente de la República, así como a su Consejo de Ministros" (Maggiolo 74).

Sin embargo, es importante señalar que el advenimiento de la dictadura no fue un evento contingente, o si se quiere, coyuntural; por el contrario, fue el resultado de un proceso gestado desde 1968 en el que las Fuerzas Armadas fueron cobrando mayor participación en la vida pública (Dufrechou 145). Uruguay pasaba entonces por una dura crisis económica que se constituyó en el acicate de las tensiones emergentes entre el Gobierno y los trabajadores.

Desde comienzos del siglo XX el país latinoamericano dependía del sector pecuario, dinamizador de su economía interna y externa: por un lado, cubría las necesidades de alimentación y vestido de los habitantes, a través de la obtención de productos como leche, carne y lana y, por otro, se consolidaba en fuente primordial de las exportaciones, por medio de su participación en el mercado internacional con productos como los cueros para abastecer la industria del calzado en Inglaterra y Estados Unidos; los tasajos de carne, vendidos a Brasil y a Cuba, y la lana, que tenía compradores en Bélgica y Francia (Minello 581).

La concentración de los habitantes en el casco urbano, azuzada por la escasa población indígena y los fenómenos migratorios europeos como causa de las guerras mundiales, precipita la industrialización de Uruguay. Para tal efecto, se invierte capital extranjero, aportado, en su mayoría, por los ingleses. La inyección de estos recursos se destinó a la industrialización, el comercio y el transporte de la producción del sector ganadero. Grupos empresariales extranjeros controlan los servicios de intermediación acaecido en las etapas de producción, transporte y consumo, lo que implica réditos para tales entidades debido a la plusvalía derivada de servicios como fletes, seguros, intermediación comercial. Pese al nuevo flujo de importaciones y exportaciones que conllevaba la modernización de Uruguay y su consecuente inversión extranjera, las leyes proteccionistas que, por ejemplo, incluían más impuestos a la importación de productos similares a los que se podían encontrar en el país, garantizaron la creación de un mercado interno. La modernización del país, auspiciada por José Batlle a través de medidas como la protección a los servicios esenciales, el gravamen a la propiedad de los terratenientes, que suponía la distribución de la renta y el surgimiento del empleo fiscal, además de la continuidad en la protección del mercado interno, llevó a la emergencia de una industrial nacional: a principios del siglo XX Uruguay contaba con industrias de alcohol, azúcar, textiles, calzado, muebles y papel, entre otras (Minello 581-584).

La crisis económica de 1929 produce un declive en el precio de las exportaciones, pues la demanda se reduce a la postre. Por su parte, las importaciones se detienen y se hace necesario que la industria nacional crezca para proveer al país con bienes que antes se traían del extranjero. En consecuencia, aumenta la demanda del sector manufacturero, la industria de la construcción se eleva y se invierte en el sector público. Una de las repercusiones de dicha inversión consiste en el crecimiento desmesurado de los funcionarios fiscales entre los años de 1938 y 1955. Con todo, es importante precisar que la economía de Uruguay seguía dependiendo, en gran medida, de sus exportaciones, por lo que fenómenos como las restricciones europeas a las exportaciones del país o la falta de acontecimientos como la segunda guerra 
o el conflicto de Corea, que habían permitido la exportación de productos derivados de la ganadería, no solo detienen el crecimiento de la industria en 1955, sino que habilitan a los dueños de la tierra (los medios de producción) a que exijan la modificación de la política de redistribución de la renta. Para la época, dicha política estaba supeditada en gran parte a las divisas obtenidas por los grupos del sector primario (terratenientes-ganaderos), quienes finalmente lograron que sus ganancias o gran parte de ellas no fueran destinadas a la redistribución de la renta para beneficiar a los más débiles y a la nueva burocracia estatal encabezada por los funcionarios públicos (Minello 584-587). Esta ruptura del Estado con los propietarios de los medios de producción, la devaluación de la moneda, la inflación venida a más, las huelgas subsiguientes, las acciones de hecho del grupo guerrillero Los Tupamaros y el consecuente intento del Gobierno por fomentar la confianza extranjera fueron algunos componentes de la crisis social uruguaya que argumentarían las medidas de control social tomadas en 1968 por parte del Gobierno.

En ese contexto, Oscar Gestido, junto con su fórmula vicepresidencial, Jorge Pacheco Areco, es elegido Presidente en las elecciones de noviembre de 1966. Su prioridad fue "controlar la inflación, que entonces sobrepasaba el cien por ciento anual. [...] pudo hacer más rigurosas las leyes sobre el recaudo de impuesto y procesar activamente a los contribuyentes infractores" (Myers 32). Además, a partir de una mayor vigilancia policial en la frontera con Brasil y los Ríos Uruguay y de la Plata, redujo el contrabando; también disminuyó las importaciones y devaluó el peso uruguayo, lo que permitió aumentar las exportaciones para enfrentar la deuda externa. Entonces había logrado menguar la inflación (32). No obstante, tras un infarto, muere repentinamente en diciembre de 1967.

Asume, entonces, la presidencia Jorge Pacheco Areco. Pese al éxito momentáneo de las medidas tomadas por Gestido, la inflación continuó subiendo, y el nuevo Presidente, ante las convenientes exigencias del Fondo Monetario Internacional devalúa el peso en un $25 \%$. Ello, desde luego, aumentaba la deuda externa, pero le otorgaba el crédito por parte del FMI que necesitaba el país. Por esa época el dólar subía, lo que implicaba refinanciar la deuda con el FMI. La crisis económica, entonces, genera protestas estudiantiles y obreras constantes, pues la inflación se traducía en la pérdida del poder adquisitivo, lo cual afectaba principalmente a las clases bajas, y es en esa coyuntura en que el nuevo Presidente declara el 13 de junio de 1968 el Estado de Sitio o, como mejor se conocía, las Medidas Prontas de Seguridad (Myers 40).

Esta figura ampliaba las facultades del Presidente a tal punto que podía suspender temporalmente algunas garantías de los individuos consagradas en la Constitución. Medidas como la militarización de los bancos y empresas estatales ante los paros, cuya primera implicación era que los empleados en caso de inasistencia al trabajo podían ser enviados a bases del ejército, el despido de líderes sindicales, la clausura de Extra y De frente (diarios izquierdistas), la prohibición a las emisoras de transmitir canciones consideradas revolucionarias, los registros continuos a los ciudadanos y la censura, mediante decreto 313, de la palabra "Tupamaros", además de otros siete términos que se referían a las guerrillas, ya empezaban a ostentar la dinámica de un régimen dictatorial, en años previos al golpe de Estado (Myers 38- 48).

En efecto, el golpe de Estado de 1973, liderado por Juan María Bordaberry, marcaría el inicio oficial de la dictadura cívico-militar en Uruguay que se extendería hasta mediados de los ochenta. Por supuesto, este país del cono sur latinoamericano no constituyó el único caso de las prácticas dictatoriales acaecidas durante la segunda mitad del siglo XX en América Latina. Chile, por ejemplo, tras el golpe al Gobierno de ala izquierda de Salvador Allende, padeció la toma del poder por parte de Augusto Pinochet en 1973; Argentina, luego de la caída del peronismo, enfrentó el mandato del general Jorge Rafael Videla en 1976, un periodo marcado - al igual que en otras dictaduras- por desapariciones, secuestros y exilios (Chaves 
168-169). Por su parte, Guatemala sufriría el genocidio bajo el mandato de José Efraín Ríos Montt en 1982. En Brasil, el golpe de Estado de 1964, que implicó la caída del presidente João Goulart, instauró la dictadura de Humberto de Alencar Castelo Branco. República Dominicana también padeció varios años de represión bajo el dominio de Leonidas Trujillo, quien se mantuvo en el poder hasta 1961, y en 1963 Joaquín Balaguer, tras un nuevo golpe de Estado, accedería al primer cargo del Estado para marcar otra edición de la dictadura (170). Finalmente en Cuba, la revolución de 1959 derrocará al dictador Fulgencio Batista y luego de algunos Gobiernos de transición, le permitirá a Fidel Castro, a quien se le ha considerado promotor de un régimen autoritario, presidir a partir de 1976 el Consejo de Estado y de Ministros.

El entorno dictatorial y autoritario de la segunda mitad del siglo XX dará lugar a prácticas literarias de representación que vincularán de forma directa el contexto histórico social y el artefacto estético, pues como sugieren Lukács y Bourdieu la producción literaria sostiene una marcada heteronomía frente a las circunstancias sociales, catalizadoras de su emergencia. En la aproximación sociocrítica de George Lukács el artefacto literario realista establece una relación insoslayable entre la presencia del ámbito social en la literatura y el arte mismo de la palabra: "La precisión histórico-social de la creación artística es, de una parte, la premisa para su carácter auténticamente realista y, por otra parte, un componente indiscutible de su eficacia" (119). Bourdieu, por su parte, introduce el concepto de campo, el cual se estructura a partir de un estado de "relación de fuerzas entre los agentes o las instituciones que intervienen en la lucha [...]" (120). Estos agentes se enfrentan con base en su capital político, económico o simbólico y con ello determinan una y otra vez la estructura jerárquica del campo. Sin embargo, los agentes no se relacionan exclusivamente con los miembros de su propio campo, sino que pueden establecer relaciones de oposición inter-campo, de manera que, por ejemplo, el campo intelectual puede oponerse al campo del poder político. Por lo tanto, el sociólogo francés planteará en Las reglas del arte un vínculo inextricable entre el artefacto literario y las condiciones sociales de su producción.

Ahora bien, es importante tener en cuenta que, por ejemplo, durante la primera mitad del siglo XX algunos escritores de Europa habían consolidado el vanguardismo literario con una relativa autonomía frente al campo social: James Joyce, Tristan Tzara, Samuel Beckett, Guillaume Apollinaire, André Bretón, Rafael Cansinos y Miguel de Unamuno, entre otros autores, procuraron centrar su escritura en la experimentación con las formas y omitieron deliberadamente la preocupación por el contexto social en gran parte de sus creaciones, pues, además de su inquietud por la escritura en sí misma, encontraron paradójicamente en esa omisión una manera de rechazar los horrores de la Primera Guerra Mundial. Por el contrario, en Latinoamérica, la aparición de realidades sociales problemáticas como las guerras civiles, la consolidación de los proyectos nacionales y el advenimiento de las dictaduras implicó una mayor producción literaria encaminada a la representación de tales circunstancias y a una clara toma de posición política frente al entorno social.

En el caso particular de las dictaduras latinoamericanas proliferó la narrativa como género literario de representación, por lo que dentro de los estudios críticos es posible hablar de la novela o la narrativa del dictador. En varias latitudes del continente es posible encontrar ejemplares diversos. Amalia, de José Mármol, es una de las obras pioneras que aborda la figura del dictador, en este caso, del argentino Juan Manuel Rosas. El señor presidente (1946), del guatemalteco Miguel Ángel Asturias, es otra novela clave del género: retrata a un poderoso dictador de una nación desconocida, pero con los rasgos megalómanos prototípicos del dictador latinoamericano. Antonio Skármeta escribe Soñé que la nieve ardía (1975), una novela que escenifica el derrumbamiento de la esperanza de cambio del pueblo chileno tras el golpe de Estado de Pinochet. En 1975 se publica El otoño del patriarca, escrita por el colombiano Gabriel García 
Márquez, novela en la que se advierte una vez más el leitmotiv del dictador solitario que domina a un país desconocido referencialmente y que accede al poder tras un golpe de Estado auspiciado por fuerzas extranjeras. En Cuerpo a cuerpo (1979) David Viñas, acudiendo a una escritura fragmentaria, reconstruye un siglo de historia del pueblo argentino, incluida la violencia que supuso la dictadura militar de Videla. La casa de los espíritus (1982), de Isabel Allende, articula, mediante una saga familiar, el mundo privado y el público a la luz de los cambios políticos que supuso la transición del Gobierno de izquierda de Salvador Allende a la dictadura de derecha de Pinochet. El cubano Reinaldo Arenas publicará en 1984 Arturo, la estrella más brillante, una obra que narra la historia de un joven homosexual encerrado en un campo de 'reeducación sexual' en Cuba. Esta novela denuncia metonímicamente la violencia y represión a la que se veían sometidos los disidentes - políticos y sexuales-durante el régimen castrista. En años posteriores, seguirá vigente el tópico dictatorial: La fiesta del chivo (2000), de Mario Vargas Llosa, con su representación del auge de la dictadura de Leonidas Trujillo y Tengo miedo torero (2001), del chileno Pedro Lemebel, constituyen dos casos paradigmáticos.

En Uruguay, tres años antes del golpe de Estado, Cristina Peri Rossi publicará, en 1970, Indicios pánicos, una obra que se podría inscribir dentro de la narrativa de la dictadura latinoamericana, pero que escapa a tal clasificación. Temáticamente se emparenta con este género, por cuanto hace patente en su escritura las prácticas de represión relacionadas con el Estado de Sitio antecedente a la dictadura. Sin embargo - y es una de las particularidades de la obra - su temporalidad fáctica e imaginaria está ubicada antes del inicio oficial de la dictadura uruguaya. Por el contrario, las obras mencionadas se ubican en años posteriores a las dictaduras de las que tratan y, aunque algunas reconstruyen sus antecedentes, ciertamente Indicios pánicos es un fenómeno sui géneris que, en lugar de mirar la dictadura en retrospectiva, es capaz de anticiparla con un lenguaje audaz e impecable.

Sin lugar a dudas, la publicación de esta obra, contemporánea al momento del Estado de Sitio en Uruguay, connota un gesto político de gran arrojo por parte de Cristina Peri Rossi. La escritora parece llamar la atención sobre un hecho que a veces pasa desapercibido: la dictadura antecede a la dictadura; es decir, existen medidas restrictivas de las libertades civiles que preparan el terreno para que la práctica oficial de la dictadura sea su exacerbado corolario. En palabras de Hernán Ramírez, "el germen de esa nueva forma de hacer política [de la dictadura] es anterior a los golpes de Estado y ya está contenido en el proceso de deslegitimación de los gobiernos constituidos. Por lo tanto, no fueron las dictaduras quienes la introdujeron, aunque indudablemente la potenciaron" (204).

Y, aun así, el conjunto de relatos breves que conforman Indicios pánicos, si bien hacen parte de la literatura comprometida en términos sartreanos, guardan un equilibrio perfecto entre la denuncia social y el tratamiento estético. Las obras pertenecientes a la novela del dictador por lo general centran su atención en la figura del déspota. No obstante, además de enunciar las prácticas represivas predictatoriales desde un género distinto a la novela, Peri Rossi logra darle un giro singularizante a su obra al enfocarla en las tensiones y en las relaciones de poder que demarcan un terreno fértil y anuncian la dictadura. De esta forma, los relatos se distancian del leitmotiv tradicional del género: la personalización de la figura del dictador, la megalomanía o la soledad de este adusto personaje. La apuesta estético política de Rossi supone más bien un abordaje ambivalente del lenguaje: por un lado, como dispositivo de representación que imita al poder hegemónico $\mathrm{y}$, por otro, como mecanismo dinámico de creación que subvierte ese mismo poder y entraña la autenticidad de los relatos. 


\section{Lenguaje y representación}

Durante los primeros años de vida aprendemos a llamar la atención del entorno inmediato usando signos que vamos aprendiendo de manera paulatina. Los gestos, el llanto y las onomatopeyas se van consolidando en formas primarias de satisfacer nuestras necesidades básicas y expresar el pensamiento. María Claudia González señala que "[1]a diferencia más notable entre nuestra especie y las demás es la facultad de comunicarse a través de la combinación de signos y sus diversas formas de expresión” (110). Se puede objetar, no obstante, que algunos animales también son poseedores de esta facultad por cuanto son capaces de transmitir mensajes a sus amos: a partir de los signos que emiten podemos entender las sensaciones de alegría, tristeza o rabia experimentadas por ellos. Sin embargo, la particularidad fundamental radica en que, a diferencia de los animales, los seres humanos, además de estar facultados para la emisión de signos naturales, crean y emplean sistemas complejos, si se quiere artificiales, para representar su realidad.

La representación permite conocer, descubrir y conservar el acontecimiento: la idea individual de mundo necesariamente pasa por el lenguaje. Desde una perspectiva lingüística, la representación tiene lugar gracias a la constitución del signo, cuya función consiste en nominar un objeto o situación de la realidad a través de la unión entre significante y (concepto) (De Saussure 93). Así, por ejemplo, para referirnos "al producto obtenido por maduración de la cuajada de la leche" (DRAE) tenemos en nuestra cabeza términos como queso, cheese o fromage, en francés.

Cada lengua tiene un amplio léxico designativo; el individuo puede escoger autónomamente, dentro del grupo conocido, cuáles son los términos que mejor se adecúan a sus propósitos. Por lo tanto, sería posible inferir que el lenguaje simplemente es un instrumento neutro al servicio de la comunicación. La aproximación que aquí se sostiene se distancia de tal consideración, pues se argumenta que el uso del lenguaje es un mecanismo que implica la asunción, el reconocimiento y el ejercicio del poder. De acuerdo con Foucault, el poder se encuentra en "la multiplicidad de las relaciones de fuerza inmanentes y propias del dominio en que se ejercen” (113) y presenta una característica fundamental, su omnipresencia: "no porque tenga el privilegio de reagruparlo todo bajo su invencible unidad, sino porque se está produciendo a cada instante, en todos los puntos, o más bien en toda relación de un punto con otro" (113). Siguiendo a Foucault, estas relaciones pueden ser de oposición o de unidad entre las fuerzas, y tales apoyos se cristalizan en los aparatos estatales, las hegemonías sociales y la formulación de las leyes.

Las manifestaciones del lenguaje no son ajenas a esta dinámica, es decir, implican relaciones de poder. Con base en los planteamientos de Ferdinand de Saussure se puede afirmar que los signos constituyentes de la lengua son de carácter arbitrario, es decir, no hay una correspondencia directa entre significante y significado, pues de ser así, existiría un solo término para referirse al concepto descrito: no habría tan amplia variedad lexical, por un lado, y tampoco existiría la diversidad de lenguas, por otro. Como lo señala el lingüista suizo la relación entre estas dos caras del signo es de carácter inmotivado; ahora bien, ello no significa que los individuos puedan escoger cualquier término de forma aleatoria para referirse a un aspecto de la realidad, sino que en virtud de una convención social se ven compelidos en el proceso de aprendizaje a nominar su mundo de acuerdo con el léxico de su lengua materna.

La adquisición de una lengua, por ende, no escapa a las relaciones de poder. De hecho, las lenguas mismas arraigan tales relaciones de fuerza entre los grupos. Basta mencionar algunos casos: "in English, we find man and mankind, which of course refer to women members of the species as well [...] Bachelor 
is at least a neutral term, often used as a compliment. Spinster normally seems to be used pejoratively" (Lakoff 74-76). Estos dos últimos vocablos en español significan, respectivamente, soltero y solterona, lo que a su vez implica la asunción de valoraciones particulares frente a las personas designadas con tales adjetivos. De esta forma, a partir de la lengua se legitiman relaciones desiguales ancladas al ejercicio del poder. Como afirma Bourdieu, los intercambios lingüísticos "son también relaciones de poder simbólico en las que se actualizan las relaciones de fuerza entre los que hablan o entre los grupos" (11). Gracias a su extensión mundial, el lenguaje deviene perfecto mecanismo para el ejercicio del poder, el cual se erige como su análogo en su papel de omnipresente. Así como todas las instituciones y los seres humanos tenemos que ver con el poder, también estamos, de manera semejante, inmersos en el lenguaje: en gran parte la política, la economía, los medios de comunicación, la ciencia y el arte se han constituido en fuerzas gracias a los usos particulares que hacen del lenguaje, en el entendido de que este es poder.

En consecuencia, la literatura, "el arte del lenguaje" (Genette 11), ejerce en un primer nivel el poder desde la representación o mímesis, una noción sobre la que se ha pensado el arte desde la antigüedad. Justamente, Platón aborda, en República III y X, el problema de la mímesis desde i) la composición poética y ii) el análisis del arte como apariencia de lo verdadero. El filósofo desarrolla el primer aspecto cuando afirma que el poeta usa tres formas distintas de narración: imitativa, en la cual se asimila "a otro en habla o aspecto"; simple, donde el poeta no se oculta detrás de un personaje -no imita-, sino que habla desde su propia voz (393c-d), y mixta, en la que se intercalan las dos anteriores (394c). En el segundo eje de análisis Platón cuestiona la imitación del pintor y del poeta debido a la consideración de la mímesis como mera apariencia de lo verdadero. El filósofo despliega el problema de la apariencia y argumenta la existencia de tres clases de objetos: los objetos en esencia, creados por Dios; los objetos determinados, fabricados por los artesanos, y los objetos imitados por el pintor. En ese orden de ideas, mientras Dios y el artesano se constituyen en artífices: el primero como creador de la idea original, y el segundo, como imitador material de esa idea, el pintor sería "imitador de aquello de que los otros son artífices" (597b-e), un reproductor de la apariencia del objeto, pero no del objeto en sí. A partir de estas ideas, Platón compara el oficio del pintor con el del poeta y se pregunta si las obras de este último estarían a triple distancia del ser. Imitar apariencias implicaba que el poeta desconocía el objeto en sí; por lo tanto, no podía opinar sobre la conveniencia de sus imitaciones, lo que resultaba problemático para el fomento de los ciudadanos de virtud que esperaba Platón en su República.

No obstante, hoy se sabe que la ponderación del trabajo artístico no se circunscribe a la imitación hiperreal de un acontecimiento, pues ello conllevaría menoscabar las posibilidades del lenguaje y de la imaginación. En todo caso, Platón era consciente del poder que ostentaba el poeta en la República, ya que en el mundo griego era una figura clave en el entretenimiento y la cohesión social: al representar las proezas de los héroes en las epopeyas y reconocer la jerarquía de las deidades en sus teogonías despertaba un sentido de propia valía e identidad entre los ciudadanos de la polis. El poder de la representación artística se hallaba, entonces, en su capacidad de difusión del statu quo para influenciar a los ciudadanos. Las sociedades posteriores, la evolución de la literatura y los acontecimientos socio-políticos mostraron que el arte no podía imitar fielmente la realidad ${ }^{2}$ máxime cuando durante épocas como la Inquisición había censores oficiales de libros o en las dictaduras se prohibía la distribución de cierta prensa o

2 Aunque el arte no pretenda establecer reproducciones fieles o incluso rechace en ciertos casos la puesta en escena del campo social, la literatura guarda un nexo imprescindible con el entorno: "permite construir mundos ficcionales que irónicamente se emparentan con el carácter inaprensible de la realidad y de nuestra condición humana” (Cuéllar 76). 
producción literaria. El poder de la representación en estos casos se define por la audacia para volver a presentar (re-presentar) desde la ficción hechos — entre ellos, los oficialmente censurados- que suscitan todo tipo de sensaciones entre los lectores.

Por su parte, Aristóteles en la Poética también aborda el arte a partir de la imitación, pero, a diferencia de Platón, no se preocupa por las condiciones de verdad de lo que imita el poeta, pues la determinación fidedigna de los hechos corresponde a la historia, no a la literatura. "En efecto, el historiador y el poeta no se diferencian por decir las cosas en verso o en prosa (pues sería posible versificar las obras de Heródoto, y no serían menos historia en verso que en prosa); la diferencia está en que uno dice lo que ha sucedido, y el otro, lo que podría suceder" (1451b). Por lo tanto, a la elaboración de una obra de arte subyacen dos componentes: la imitación (representación) y la creación (verosimilitud); en términos aristotélicos, "el poeta es imitador, lo mismo que un pintor o cualquier otro imaginero, necesariamente imitará siempre de una de las tres maneras posibles; pues o bien representará las cosas como eran o son, o bien como se dice o se cree que son, o bien como deben ser" (1460b). En suma, Aristóteles abre la puerta a otro tipo de representación: la mímesis creadora.

\section{Representación en Indicios pánicos}

Desde la perspectiva aristotélica del arte es posible la coexistencia de la imitación y la actitud creadora; por el momento, y atendiendo a los motivos de análisis, se hará mayor énfasis en la imitación, aunque resulta pertinente aclarar que en los relatos de la obra convergen los dos fenómenos: esos indicios que cobijan la totalidad del texto son huellas, señales, que dejan una parte de realidad y un espacio vacío donde se aloja la imaginación. Así las cosas, veremos cómo la representación en Indicios pánicos actualiza las relaciones de poder que se ejercieron en la Uruguay comprendida entre 1968 y 1970.

En el primer relato de la obra se narra la historia de un estudiante que es agredido violentamente por miembros del ejército en medio de una protesta:

Después un policía me llevó a prestar declaración: quería que testimoniara cómo una hoja de plátano lanzada por un joven fue a darle en la cara a un cabo y al rozarle un ojo, lagrimeó un poco. El joven fue reprimido violentamente por los demás soldados, quienes lo echaron sobre el suelo y lo rociaron con gasolina. Después de mojado, cada soldado se acercaba a echar un fósforo. Ardió durante unos minutos después se hizo cenizas.

\section{$[\ldots]$}

Desde que los estudiantes han adquirido la peligrosísima costumbre de enfrentar a los soldados con hojas caídas de los árboles, éstas han pasado a ser consideradas por el gobierno como armas ofensivas contra la seguridad del Estado. (Peri Rossi 15-16)

Se ponen de presente las relaciones de poder entre dos grupos, en este caso por oposición. Hablamos de representación porque la autora se vale de acontecimientos históricos puntuales de la época (las huelgas, protestas estudiantiles y obreras, marchas, disturbios, etc.) para la construcción de su relato. En la fábula se evidencia un tipo de relación desigual, advertida por la clase de 'armas' que utiliza cada grupo, y que 
se acentúa por la ironía de situación (Schoentjes 14) que propone el final del relato: lo preocupante no es la incineración del estudiante, es la adquisición de hojas para defensa personal... En consecuencia, la representación irónica del Estado y de las fuerzas militares reduce al absurdo sus acciones; sin embargo, manifiesta su poder: solo a quienes han adquirido una autoridad desmedida les es lícito justificar el absurdo en nombre de una seguridad estatal en abstracto.

La situación de quienes protestan, incluida la de los estudiantes, va a ser objeto de representación en los relatos de Indicios pánicos, ya sea como tema central o a manera de comentario periférico: “[...] y los rengos, quietos, se apoyaban en una sola pierna, la que les quedaba buena, después del asalto a la universidad, cuando los policías y los soldados tiraron para todos lados" (Peri Rossi 102). No hay que olvidar que este comentario 'suelto' en la representación ficcional tiene su correlato histórico: en agosto de 1968, tras el secuestro del presidente de la telefónica estatal, Ulysses Reverbel, por parte del Movimiento de Liberación Nacional-Tupamaros, la policía entra a la Universidad de la República pensando que allí se encontraba el funcionario raptado, donde tiene lugar un cruento enfrentamiento con los estudiantes. La consecuencia: varios heridos y el primer estudiante muerto, Líber Arce (Myers 52). Se insiste nuevamente en la necesidad de representar los excesos de las fuerzas armadas a partir de los cuerpos lastimados; el asalto a la Universidad, por su parte, sugiere una mirada sospechosa hacia los estudiantes o una excusa 'legítima' para aplicar la fuerza. La autora deja entonces un indicio mimético claro de lo que efectivamente acontecería en los años sucesivos: cuando se había terminado de instaurar la dictadura se militarizó la Universidad (Ruffinelli 22).

De forma análoga, la representación que hace Peri Rossi de los intelectuales de la época se asemeja bastante a las condiciones reales por las que pasaba este gremio. Carlos Real de Azúa hace una ilustración al respecto:

[L]os responsables de la gestión del período han ahondado y sistematizado una marginación del intelectual que era ya toda una tradición de la política uruguaya. Pero en tal sentido, y sobre todo en sus expresiones más típicas del hombre de ciencia, el profesor y el escritor, la exclusión del intelectual de todos los cargos y funciones que reclaman específicamente su presencia y su asistencia se ha dado con un método y un rigor extremos (162).

Entonces, se avanzaba en el incremento de la fuerza policial, mientras se retrocedía en otros ámbitos importantes como el arte, la cultura y, en general, la educación. El docente representaba un peligro para la estabilidad del régimen, era un sospechoso más.

-Es un ciprés de la India - dice el profesor que mendiga. Mendiga para poder comprar el material con el que tiene derecho a dictar las clases. Las clases nunca se le pagan, porque el estado piensa que es un privilegio dictar clases, y aquel que aspira a hacerlo debe anotarse en una lista en el Ministerio del Interior. Allí los aspirantes son rigurosamente analizados; se investigan sus pensamientos, se les examina políticamente, remontándose a la ideología de sus antepasados: el estado no puede permitirse el lujo de dejar la educación en manos de elementos peligrosos para su seguridad. (Peri Rossi 36)

Las relaciones de fuerza entre intelectuales, estudiantes y Estado son manifiestas. Aunque el poder ejercido por el aparato estatal se impone, este reconoce un potencial peligro en la figura del intelectual, pues está en la capacidad no solo de ejercer la crítica, sino de tener un impacto en la sociedad a través de sus artículos en prensa o, incluso, en las clases impartidas. 
En efecto, ya desde el 68 se venía interviniendo la Universidad de la República para buscar subversivos en contra del Gobierno de turno. Precisamente, en 1973 tras el golpe de Estado varios directivos de la Universidad fueron despojados de sus cargos junto con varios docentes de la Universidad, y el Estado vuelve ilegales a los grupos de izquierda para desarticular su presencia en el claustro universitario (Universidad de la República de Uruguay, párr. 1-7).

En el relato de Peri Rossi se representa la precariedad del intelectual uruguayo durante la época dado que menguar sus ingresos era una forma de marginarlo para garantizar el statu quo promovido por el Gobierno. El recurso hiperbólico de la mendicidad para comprar el material con el que tiene derecho a enseñar el profesor, así como la parodia a la voz del Estado que no puede permitirse el lujo de dejar la educación en manos de elementos peligrosos evidencian la censura de la que eran objeto ciertos libros y los docentes: la mímesis aquí denota el poder de las medidas represivas, pero no se trata únicamente de una representación pasiva, la voz narrativa se erige contrahegemónica en el uso de tales figuras retóricas que devienen mímesis creadora y que implican una toma de posición crítica frente a la censura y la consecuente marginalización del intelectual.

De hecho, la publicación de Indicios pánicos en plena vigencia del Estado de Sitio en 1970 es un acto de absoluta valentía y de toma de posición por parte de Cristina Peri Rossi y de la editorial en la que aparecieron estos relatos por primera vez, Nuestra América. A pesar de que ya el intelectual era observado con sospecha y de que un cuestionamiento abierto a las medidas represivas y las fuerzas estatales podía suponer la pérdida de estabilidad económica propia, la prisión o el exilio, Peri Rossi decide anteponer su compromiso est-ético, incluso a riesgo de perder su estabilidad en la Uruguay de la época.

El libro, entonces, permite advertir la representación de un intelectual precarizado que debe ceñirse a las normas del régimen, pero en su conjunto y visto como objeto cultural, hecho lenguaje representativo, para la recepción del público, marca la presencia de Cristina Peri Rossi como una intelectual comprometida que desde su oficio ejerce un poder contrahegemónico frente a la realidad de su entorno.

Precisamente, el actuar de Peri Rossi se corresponde de manera estricta con la orientación del intelectual que propone Edward Said: "[...] ser alguien cuya misión es la de plantear públicamente cuestiones embarazosas, contrastar la ortodoxia y [el] dogma, actuar como alguien al que ni los gobiernos ni otras instituciones pueden domesticar fácilmente [...]. (30). La alternativa de la escritora fue combatir el absurdo a través de la representación creadora, de su literatura. La respuesta del régimen, sin embargo, fue tan deleznable como lapidaria: prohibieron sus libros, vetaron su ejercicio periodístico, la destituyeron de su cátedra de literatura, prohibieron la mención de su nombre y le quitaron la nacionalidad uruguaya (Entrevista a Cristina Peri Rossi párr. 2). Por esta razón, Cristina Peri Rossi tendrá que exiliarse de su país en 1972 para radicarse definitivamente en España. En últimas, buscaron anular su representación, su voz, pues esta clase de regímenes son conscientes del poder del lenguaje: dejar de nombrar es hacer desaparecer. Con todo, la posición crítica de la autora frente a las prácticas dictatoriales no se logró silenciar definitivamente, más tarde, en 1981, la editorial española Bruguera hará una reedición de Indicios pánicos que permitirá al mundo europeo conocer, desde la literatura, el régimen uruguayo que precedió a la dictadura. 


\section{Lenguaje: una forma de construir la realidad}

En Indicios pánicos la censura se configura, en términos de Greimas (ctd. en Eco), como una isotopía textual que atraviesa los relatos y que permite aproximarse a la obra de Peri Rossi en clave de filosofía del lenguaje, de su poder. De acuerdo con uno de los relatos, la censura solo permitía olvidar (64). Y es que, en realidad, el Ministerio del Interior, prohibió a los medios de comunicación usar expresiones como "delincuente político", "subversivo", "célula", "extremistas" y en su lugar debían emplear "reo", "malhechor", delincuente (Real de Azúa). Por supuesto, la idea era construir un imaginario frente a los presos que deviniera realidad. "Nuestra conducta y percepción, nuestra lógica y nuestro pensamiento, entran dentro del control de un sistema de lenguaje" (Mills 340-341). El lenguaje entendido desde la construcción, entonces, se convierte en un instrumento poderoso.

[s]e han eliminado tantos términos, que, en definitiva, solamente ha quedado la posibilidad de no hablar de ella, ignorarla, desconocerla, hacer como que no existe. Ningún término, al final, era posible de ser pronunciado sin ser víctima de una denuncia por transgredir tal o cual disposición, por lo cual, evitamos rozar los temas vinculados a ella. (Peri Rossi 110)

Siguiendo a Foucault (2005), la censura "liga lo inexistente, lo ilícito y lo informulable de manera que cada uno sea a la vez principio y efecto del otro: de lo que está prohibido no se debe hablar hasta que esté anulado en la realidad" (103). Por lo tanto, la palabra otorgará existencia a las ideas que busca promover la dictadura, mientras su ausencia, aunque no implica su desaparición factual, sí conlleva la anulación de su carga ética.

La autora en este caso transita de un lenguaje mimético creador para representar y cuestionar la realidad hacia la representación de un lenguaje censurado, apocado. No obstante, en los pronombres enclíticos, "ignorarla, desconocerla...", se alude a la dictadura sin mentarla. Nombrar, aunque sea por alusión, es mantener la tensión entre las relaciones de poder. Por lo tanto, la dictadura pretende controlar el lenguaje, una esfera personal y social no estática ni estatizable. Busca evitar la representación para anular la existencia y constituir la realidad más conveniente al régimen.

Representar y crear confluyen en el lenguaje artístico en la noción de espejo. Desde luego, no se trata de la imitación ceñida del todo a la realidad. Se trata, más bien, de un espejo cuyos reflejos son parciales, refracciones, y, aun así, su función no es la de la mera reproducción; por el contrario, es un mecanismo revelador (Macherey 139; Voloshinov 20-21). Lo dado y lo creado hacen parte de un todo artístico que siempre crea algo nuevo (Bajtin 312). Cristina Peri Rossi tiene la facultad de aludir a la dictadura, de hacerla aparecer de nuevo, pues solo en su aparecer puede enfrentarse (resulta difícil luchar contra lo que en apariencia no existe), por ende, la convoca a través de mímesis, pero es una mímesis creadora: en la obra hay elementos paródicos, fantásticos e irónicos, que llevan a la dictadura al absurdo. En palabras de Bajtin: "Pero la verdad opuesta a la mentira casi no consigue tener en ninguna expresión intencional-verbal directa su propia palabra; solo suena esta en la acentuación paródica-desenmascaradora de la mentira. La verdad se restablece llevando la mentira al absurdo" (127). Es esa la propuesta de la uruguaya: revelar la lógica interna de la dictadura, representarla desde la apuesta estética y no sucumbir a la amenaza. 


\section{Conclusiones}

Con respecto al planteamiento inicial se logra constatar que el lenguaje en la obra Indicios pánicos actualiza las relaciones de poder durante la predictadura uruguaya. Sin embargo, no solo renueva el nexo jerárquico de un poder ejercido 'de arriba hacia abajo', sino que pone de presente, en la toma de posición del narrador, el ejercicio de un poder contrahegemónico. El recurso estético de la obra es analizado en esta perspectiva como una forma de reducir al absurdo las prácticas dictatoriales; es decir, en tanto mecanismo que guarda cierta heteronomía frente a la postura crítica. Un estudio posterior podría indagar la escritura fragmentaria, el uso del aforismo, del microrelato, los dispositivos fantásticos y otros recursos estéticos de la obra como elementos de relativa autonomía que harían parte de una poética vanguardista de la autora o acaso de una 'vanguardia comprometida'. Al respecto, un estudio clave inicial lo constituye el trabajo de Esther Raventós-Pons, quien analiza el expresionismo en esta obra de predictadura y establece un contrapunto con la pintura "El grito" de Edvard Munch.

Este artículo definitivamente constituye un aporte al campo de la crítica literaria sobre Indicios pánicos, una obra de crítica escasa: pocas reseñas y contados artículos de investigación son el común denominador en el entorno académico frente al libro. Probablemente este fenómeno puede explicarse a partir del vacío cultural en el que la dictadura sumió a Uruguay. En este sentido, Ruffinelli señala que parte de la crítica literaria se ejercía a través de la prensa alternativa o las revistas, y al ser estas objeto de censura y represión, la presencia de la crítica literaria decayó a tal punto que las revistas precedentes a la dictadura desaparecieron (23-25). Esta situación se aúna al veto de los libros de la autora y a la caída de la producción literaria durante el periodo de la represión: 1973-1984.

\section{Referencias}

Aristóteles. Poética. Edición trilingüe por Valentín García Yebra. Madrid: Editorial Gredos, 1975.

Bajtin, Mijail. Teoría y estética de la novela. Madrid: Taurus, 1989.

Bajtin, Mijail. Estética de la creación verbal. México D. F.: Siglo XXI editores, 2003.

Blengio Brito, Raúl. La nueva legislación de prensa uruguaya. Revista comunicación y medios, 6 (1988): $135-146$.

Bourdieu, Pierre. ¿Qué significa hablar?: Economía de los intercambios lingüísticos. Madrid: Ediciones Akal, 1985.

Bourdieu, Pierre. Campo de poder, Campo intelectual: itinerario de un concepto. Buenos Aires: Editorial Mortressor. 2002.

Bourdieu, Pierre. Las reglas del arte. Barcelona: Editorial Anagrama. 2002.

Chaves Palacios, Julián. Dictaduras y gobiernos autoritarios en Iberoamérica en el siglo XX: Violencia, derechos humanos y procesos de construcción de la memoria. En: Diálogos latinoamericanos, 20, (2013): 162-181.

Cuéllar Aragón, Danny. In Absentia: de la realidad fragmentaria a la ficción ineludible en la novela Mañana en la batalla piensa en mí de Javier Marías. Hojas De El Bosque, 4(7), (2018): 68-76. https://doi.org/10.18270/heb. $\underline{\mathrm{v} 4 \mathrm{i} 7.2718}$

Eco, Umberto. Lector in fabula. La Cooperación interpretativa en el texto narrativo. (Ricardo Pochtar, Trad.). Barcelona, España: Editorial Lumen, 1981.

De Saussure, Ferdinand. Curso de lingüística general. Buenos Aires: Editorial Losada, 1945.

Dufrechou, Luis. Crisis Liberal en Uruguay: violencia política y autoritarismo (1967-1985). Cuadernos iberoamericanos. Revista de historia y comunicación, 1 (2015): 144-160.

Foucault, Michel. Historia de la sexualidad: La voluntad del saber. México D. F.: Siglo XXI editores, 2005.

Genette, Gerard. Ficción y dicción. Barcelona: Editorial Lumen, 1993. 
González, María Claudia. El origen del lenguaje y origen del habla. En Litterae seminario Andrés Bello, 8 (1999): 109-118.

Informe sobre la situación de los derechos humanos en Uruguay. Comisión Interamericana de Derechos Humanos, OEA, 1978. Recuperado de http://www.cidh.org/countryrep/Uruguay78sp/indice.htm

Lakoff, Robin. Language and Woman's Place. En Language in society, (2), 1 (1973): 45-80. https://doi.org/10.1017/ $\underline{\text { S0047404500000051 }}$

Lukács, George. Significación actual del realismo crítico. (M. Toral, Trad.). México, D.F.: Ediciones Era. 1963 (Obra original publicada en 1958).

Macherey, Pierre. Lenin, critic de Tolstoi. En Revista de la Dirección de Divulgación Cultural Universidad Nacional de Colombia, 1970.

Maggiolo, Oscar. Uruguay, tres años de dictadura. Revista nueva sociedad, 27 (1976): 74-84.

Mills, Charles. El lenguaje, la lógica y la cultura. En Poder, política y pueblo. México: Fondo de Cultura Económica, 1964.

Minello, Nelson. Uruguay: la consolidación del Estado militar. Revista mexicana de sociología, (39), 2 (1977): 575594. https://doi.org/10.2307/3539778

Myers, Scott. Los años oscuros: Uruguay 1967-1987. Montevideo: Editorial Latina, 1977.

Peri Rossi, Cristina. Indicios pánicos. Barcelona: Editorial Bruguera, 1981.

Platón. República. Edición bilingüe Trad. J. M. Pabón \& M. Fernández-Galiano. Tomo II. Madrid: Instituto de Estudios Políticos, 1949.

Ramírez Hernán. Las dictaduras del cono sur y el giro de las políticas económicas. En: Boletín Americanista, (1), 72. (2016): 199-220.

Raventós-Pons, Esther. El Expresionismo en "Indicios pánicos” de Cristina Peri Rossi y “El grito" de Edvard Munch. En: Revista Hispánica Moderna, 2. (2000): 482-499.

Real Academia Española. Diccionario de la lengua española, 23. a ed. Madrid: Espasa, 2014.

Real de Azúa, Carlos. Política, poder y partido en el Uruguay de hoy, 1971.

Rico, Álvaro. Cómo nos domina la clase gobernante: Orden político y obediencia social en la democracia posdictadura Uruguay (1985-2005). Montevideo: Ediciones Trilce, 2005.

Ruffinelli, Jorge. La crítica y los estudios literarios en el Uruguay de la dictadura (1973-1984). En: Hispanoamérica, 56/57. (1990): 21-29.

Said, Edward. Representaciones del intelectual. Barcelona: Ediciones Paidós Ibérica, S.A. 1994.

Suburbano. Entrevista a Cristina Peri Rossi. 2014. Recuperado de : $\underline{\text { https://suburbano.net/entrevista-a-cristina- }}$ peri-rossi/

Schoentjes, Pierre. Poética de la ironía. Madrid: Cátedra, 2003.

Universidad de la República de Uruguay. El rol de denuncia que tuvo la Universidad de la República en tiempos dictatoriales. Recuperado de: http://www.bienestar.edu.uy/content/el-rol-de-denuncia-que-tuvo-launiversidad-de-la-republica-en-tiempos-dictatoriales

Voloshinov, Valentín. El signo ideológico y la filosofía del lenguaje. Buenos Aires: Ediciones Nueva Visión, 1976. 